ORIGINAL ARTICLE

\title{
Adrenocortical adenomas with regression and myelolipomatous changes: urinary steroid profiling supports a distinctive benign neoplasm
}

\author{
Victoria Perna*, Norman F. Taylort, Dorota Dworakowskał’§, Klaus-Martin Schulteף’**, Simon Aylwin $\neq$, \\ Fatima Al-Hashimi†† and Salvador J. Diaz-Cano†† \\ *Department of Biochemistry, Hospital Universitario "V Macarena", Seville, Spain, †Department of Biochemistry, King's College \\ Hospital and King's Health Partners, $\ddagger$ Department of Endocrinology, King’s College Hospital and King's Health Partners, London, \\ UK, §Department of Endocrinology and Medicine, Medical University, Gdansk, Poland, $\mid$ Department of Endocrine Surgery, King's \\ College Hospital and King's Health Partners, London, UK, ${ }^{*}$ Department of Surgery, John Curtin School of Medical Research, \\ Australian National University, Canberra, ACT, Australia and ††Department of Histopathology, King's College Hospital and King's \\ Health Partners, London, UK
}

\section{Summary}

Background Adrenocortical neoplasms are classically divided into adenomas (ACA) and carcinomas (ACC). Heterogeneous appearance and greater size are criteria to suggest malignancy, along with the urinary steroid profile (USP). The presence of regression and myelolipomatous changes in adenomas (ACARML) can contribute to confusion with ACC and its USP remains unknown.

Objective To evaluate the features of ACA-RML in comparison with other adrenocortical neoplasms.

Methods We selected consecutive ACA (11), ACA-RML (7) and ACC (13) cases for which USP analysis was performed before surgery and tissue was available for histological evaluation (King's College Hospital, 2005-2012). Cases were classified according to $\mathrm{WHO}$ and Armed Forces Institute of Pathology criteria. USPs were obtained by gas chromatography/mass spectrometry. Total excretion of individual steroids and indices (sums and ratios chosen to reflect steroid metabolic activity) were compared between ACA-RML, ACA and ACC.

Results In comparison with ACA, tumours in ACA-RML were significantly larger $(8.5 \pm 2.4$ vs $3.5 \pm 1.0, P=0.002)$, presented in older patients and showed relatively higher incidence in males. Mitotic figure counts were significantly lower $(0.39 \pm 0.04$ vs $0.93 \pm 0.11$ in ACA, $P=0.001)$ and revealed higher frequency of apoptotic cells $(100 \%$ vs $9 \%$ in ACA, $P=0 \cdot 001)$. The USP of ACA-RML showed no diagnostic features of ACC. No differences from ACA were significant, but

Correspondence: Salvador J. Diaz-Cano, King's College Hospital, Dept. Histopathology, Denmark Hill, London, SE5 9RS, UK. Tel.: +44 20 3299-3041; Fax: +44 20 3299-3670; E-mail: sdiaz-cano@nhs.net there was a tendency towards lower dehydroepiandrosterone DHA and DHA metabolites.

Conclusions ACA-RML reveals distinctive histological features and lack of USP markers of malignancy. More cases of this rare tumour may confirm differences from ACA in steroid excretion. It is important to recognize ACA-RML because its size and heterogeneous appearance raise the possibility of ACC.

(Received 3 February 2014; returned for revision 25 March 2014; accepted 26 March 2014)

\section{Introduction}

Adrenocortical proliferative lesions represent a heterogeneous group comprising nodular hyperplasias, adenomas (ACA) and carcinomas (ACC). ${ }^{1-4}$ Clues that should alert clinicians to the possibility of malignancy include the following: tumour size $>4$ $5 \mathrm{~cm}$ in diameter, imaging features of calcification, blurred margins, an irregular shape, heterogeneous contrast enhancement and distant metastases on computed tomography, together with hormonal overproduction in more than one adrenocortical axis. $^{5,6}$ In contrast, adenomas are smaller, smooth shaped and with homogeneous enhancement.

A minority of adenomas resemble carcinomas in being large, with heterogeneous appearance frequently related to regressive/ degenerative changes, which contribute to a more difficult preoperative diagnosis, especially when the changes are extensive. The criteria used to identify these changes are not clearly defined but include haemorrhage, fibrin deposition, interstitial hyalinization, cystic changes, adipose tissue infiltration and extramedullary hematopoiesis, with or without calcification or ossification. ${ }^{7,8}$ To date, adrenocortical adenomas with extensive regressive changes are extremely rare and are reported as single cases or very short series only. 
The adrenal cortex produces cortisol, corticosterone and C19 steroids. These are metabolized in the liver and the kidney and then excreted in the urine either in the form of free steroids or conjugated with sulphuric or glucuronic acid. The urinary steroid profile (USP) has proved to be very useful in the identification of carcinomas, ${ }^{9,10}$ but findings in adenomas with regression and myelolipomatous changes (ACA-RML) have not been previously reported. Here, we described clinical, histological and USP features of seven cases of this very rare adenoma subtype in comparison with those of conventional adrenocortical adenomas and carcinomas. We aimed to determine if the steroid profile in the ACA-RML group could be securely distinguished from ACC. We further compared this group with ACA and explored whether any differences found might be related to the histological changes.

\section{Methods}

\section{Selection and description of participants}

All adrenocortical proliferative lesions available at King's College Hospital (Dept Histopathology, 1988-2012) were reviewed, including nodular hyperplasias (44), adenomas (118) and carcinomas (28). From this series, extensive regressive myelolipomatous changes (present in at least one-third of the tumour) were observed in 7 ACA (2005-2012); erythroblasts and red blood cells closely collocated with macrophages containing hemosiderin with or without megakaryocytes were required in the focus to identify the myeloid component. During this period, all consecutive ACA (11), ACA-RML (7) and ACC (13) had urine steroid profiles performed before surgery and histopathology available for evaluation and were selected for this analysis. Myelolipomas in the context of hyperplastic conditions (such as congenital adrenocortical hyperplasia or Cushing's disease) were excluded from this study. Conventional ACA and ACC were used as benign and malignant controls, respectively.

The clinical syndrome was investigated in each case by standard clinical and laboratory approaches, including basal hormone determination, along with stimulation and suppression tests if necessary and imaging methods. ${ }^{4,11-13}$ The bare adrenal weight was also recorded in each case.

\section{Histologic criteria and classification}

All surgical specimens were serially sectioned and routinely processed for histological diagnosis and sampled with at least 1 block per $\mathrm{cm}$ of maximum lesion diameter. The cases were classified according to the World Health Organization and Armed Forces Institute of Pathology criteria ${ }^{12,13}$; if there were proven metastases, they were classified as malignant. All haematoxylin and eosin-stained sections were evaluated histologically and graded by two of the authors (both pathologists, FAH and SDC) independently, using criteria previously described. ${ }^{3}$ In case of grading disagreement, the lesions were discussed during simultaneous inspection before final categorization. Reproducibility data were not recorded. Standard scores for the classification of these lesions ${ }^{4,14,15}$ were also registered; as the benign group scores low figures (up to 2), ${ }^{14,15}$ no further analysis was performed with these scores in the distinction of ACA-RML from ACA and ACC.

\section{Urinary steroid profiling}

Examination of 24-h urinary steroid metabolite excretion was carried out using gas chromatography/mass spectrometry (GC/ MS). A detailed description of this methodology has been published. ${ }^{16}$ In summary, free and conjugated steroids were extracted from $10 \mathrm{ml}$ urine by solid-phase extraction. Steroid conjugates were enzymatically hydrolysed, reextracted, and chemically derivatized to form methyloxime-trimethylsilyl ethers. GC/MS was carried out on a Clarus $50{ }^{\circledR}$ instrument (Perkin-Elmer, Waltham, MA, USA).

The steroid metabolites quantified in our study are listed in supplemental Table 1 and the calculated sums and ratios in supplemental Table 2. Levels of steroid metabolite excretion were expressed as $\mu \mathrm{g} /$ day. Supplemental Figure 1 shows the metabolic relationships of the studied steroids. Other steroids that have proved to be useful markers of ACC were also compared empirically between groups. These included tetrahydro-11-deoxycortisol (16), pregnene-3,16,20-triols (15), 16a- and 21hydroxypregnenolone and tetrahydro-11-deoxycorticosterone.

\section{Statistics}

Total excretion of individual steroids and steroid indices were compared between ACA-RML, ACA and ACC groups using the Kruskal-Wallis nonparametric test; for significance, values of $P<0.05$ and pair-wise comparisons were carried out using Dunn's post hoc test.

\section{Results}

Clinical characteristics of the patient groups are listed in Table 1 .

\section{Histological features}

$A C A-R M L$. (Figure 1)After removing the adipose tissue, the adrenal glands weighed $291.4 \pm 366.3 \mathrm{~g}$. Histologically, the peritumoral gland was atrophic in five cases (71\%) and unremarkable in two cases (29\%). The tumours showed an alveolar growth pattern in four cases $(57 \%)$ and a trabecular pattern in 3 (43\%). Cytologically, tumours composed of foamy clear cells predominated in this series (5 cases, 71\%) and no pigment-containing cells were observed.

Small nonconfluent necrotic foci were present in two cases (29\%) and isolated apoptotic cells in all seven cases (100\%). No or minimal inflammatory response was found, predominantly lymphocytic (6 cases, 86\%). Myxoid stromal reaction was observed in five cases $(71 \%)$ and no desmoplastic tissue was observed. No capsular, lymphovascular, sinusoidal or 
Table 1. Clinical findings of patients with adrenocortical adenoma (ACA), adrenocortical adenoma with regression and myelolipomatous changes (ACA-RML) and adrenocortical carcinomas (ACC)

\begin{tabular}{llll}
\hline & ACA $(n=11)$ & ACA-RML $(n=7)$ & ACC $(n=13)$ \\
\hline Age at presentation (years), Av \pm SD (Range) & $54 \cdot 3 \pm 12 \cdot 35(38-70)$ & $70 \cdot 14 \pm 8 \cdot 84(57-79)$ & $51 \cdot 7 \pm 16 \cdot 2(26-76)$ \\
Sex & $\mathrm{F}-9(82 \%)$ & $\mathrm{F}-3(43 \%)$ & $\mathrm{F}-9(69 \%)$ \\
Female (\%), male (\%) & $\mathrm{M}-2(18 \%)$ & $\mathrm{M}-4(57 \%)$ & $\mathrm{M}-4(31 \%)$ \\
Size of adrenal nodule (cm), Av \pm SD (Range) & $3 \cdot 5 \pm 1 \cdot 0(2 \cdot 5-6)$ & $8 \cdot 5 \pm 2 \cdot 4(5 \cdot 5-13)$ & $13 \cdot 9 \pm 4 \cdot 8(7 \cdot 0-25 \cdot 0)$ \\
Endocrine syndrome at presentation & & 5 & 3 \\
$\quad$ Cushing's & 9 & 0 & 3 \\
$\quad$ Conn's & 2 & 0 & 9 \\
$\quad$ Mixed (androgen, glucocorticoid) & 0 & $1(0-2)$ & $6(3-9)$ \\
$\quad$ Mass only & $1(0-2)$ & & \\
Weiss score * Median (Range) & & \\
\hline
\end{tabular}

*The Weiss system scores the presence or absence of nine histopathological features (Weiss score range $0-9$ ); scores under 3 are indicative of a benign adrenal tumour, scores of 3 and above are indicative of malignancy ${ }^{14}$. As Weiss scores are pure diagnostic markers and provided no additional prognostic information, no further investigation was carried out with them ${ }^{14,15}$.

perineural invasion was identified. Haemorrhage and stromal hyalinization with myelolipomatous changes as inclusion diagnostic criteria were present in at least $1 / 3$ of the neoplasm in all seven cases.

Nuclear features disclosed low grade (6 cases, 86\%), prominent anisokaryosis (6 cases, $86 \%$ ), mild pleomorphism (5 cases, $71 \%$ ), fine chromatin distribution (5 cases, $71 \%$ ), inconspicuous nucleoli (6 cases, 86\%), and low nucleus-cytoplasm ratio (4 cases, 57\%). Nuclear pseudoinclusions were observed in 2 cases (29\%) and multinucleated cells in 3 cases (43\%). The mitotic figure (MF) counting was $0 \cdot 39 \pm 0 \cdot 04 \mathrm{MF} / 50 \mathrm{HPF}$ with no atypical mitoses.

Aca. After removing the adipose tissue, the adrenal glands weighed $47.9 \pm 92.6 \mathrm{~g}$. Histologically, the peritumoral gland was atrophic in nine cases $(82 \%)$ and unremarkable in two cases
(18\%). The tumours showed an alveolar growth pattern in four cases $(36 \%)$ and a trabecular pattern in $4(36 \%)$, and were nodular in $3(28 \%)$. Cytologically, tumours composed of foamy clear cells predominated in this series (7 cases, 64\%) and two cases $(18 \%)$ had pigment-containing cells.

Small nonconfluent necrotic foci were present in one case (9\%) and occasional isolated apoptotic cells in one case (9\%). No or minimal inflammatory response was found, predominantly lymphocytic (10 cases, 91\%). A myxoid stromal reaction was observed in two cases (18\%) and no desmoplastic tissue was observed. No capsular, lymphovascular, sinusoidal or perineural invasion was identified.

Nuclear features disclosed low grade (9 cases, $82 \%$ ), prominent anisokaryosis (10 cases, $91 \%$ ), mild pleomorphism (8 cases, $73 \%$ ), fine chromatin distribution (7 cases, 64\%), inconspicuous nucleoli (9 cases, 82\%), and low nucleus-cytoplasm ratio
Fig. 1 Pathologic features of ACA-RML. This ACA subtype revealed haemorrhagic and fibrinous foci irregularly distributed, along with areas of adipose tissue (a). These findings were confirmed histologically by the presence of trabecular-nested cortical tumour cells, along with interstitial mature adipose tissue and myeloid elements (b, HE 100x), hyalinized eosinophilic material (c, HE 100x) and erythroblasts (d, HE 200x).
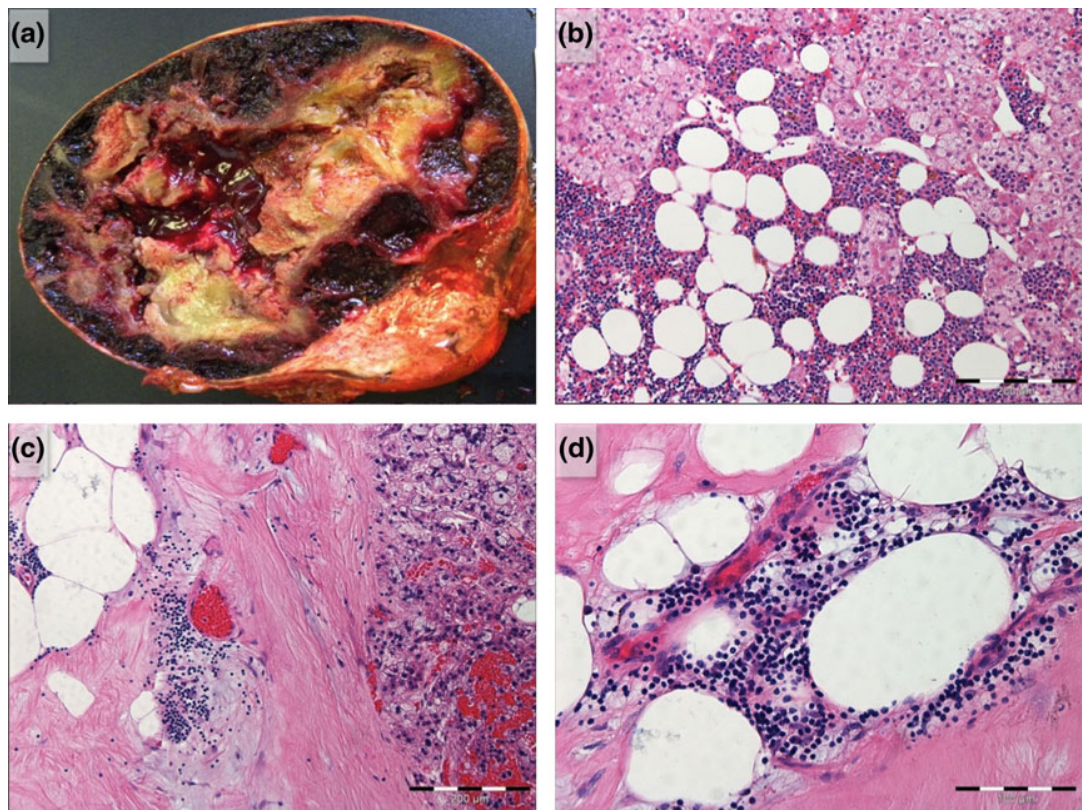
(6 cases, 55\%). Nuclear pseudoinclusions were observed in three cases $(27 \%)$ and multinucleated cells in five cases $(45 \%)$. The MF counting was $0.93 \pm 0 \cdot 11 \mathrm{MF} / 50 \mathrm{HPF}$ with no atypical mitoses.

Acc. After removing the adipose tissue, the adrenal glands weighed $470 \cdot 0 \pm 590.8 \mathrm{~g}$. Microscopically, the peritumoral gland was atrophic in 1 case $(8 \%)$, hyperplastic in $1(8 \%)$ and unremarkable in 11 cases (84\%). The tumours displayed diffuse growth patterns in eight cases (61\%), insular in $3(23 \%)$, nodular in $1(8 \%)$ and trabecular in $1(8 \%)$. Cytologically, all tumours predominantly revealed eosinophilic cells. Cytoplasmic pigment was seen in one case $(8 \%)$.

Tumour cell necrosis was frequently observed (9 cases, $69 \%$ ), with confluent (6 cases, $46 \%$ ) or perithelial patterns (3 cases, 23\%). In addition, apoptotic cells were present in 10 cases $(77 \%)$, but associated with lymphocytic satellitosis in only four cases $(31 \%)$. The inflammatory response was minimal (10 cases, 77\%), predominantly lymphocytic (6 cases, $55 \%)$. Stromal reactions were observed in 10 cases $(77 \%)$, desmoplastic in $9(69 \%)$ and myxoid in 1 (8\%). Local staging showed extracapsular extension in seven cases (54\%), blood vessel invasion (capsular in 6 cases, $43.8 \%$ and extracapsular in $2,15 \%)$. Only one case ( $8 \%$ ) showed perineural invasion.

Nuclear features displayed high grade (12 cases, 92\%), prominent anisokaryosis (13 cases, 100.0\%), severe pleomorphism (12 cases, 92\%), coarse chromatin (10 cases, 77\%), inconspicuous nucleoli (10 cases, 77\%) and low nucleus-cytoplasm ratio (9 cases, 69\%). Nuclear pseudoinclusions were present in three cases $(23 \%)$ and multinucleated cells in $4(31 \%)$. The MF counting was $17 \cdot 38 \pm 0 \cdot 57 \mathrm{MF} / 50 \mathrm{HPF}$ with atypical mitoses in nine cases (69\%, indexing $1.95 \pm 2 \cdot 94 / 50 \mathrm{HPF})$.

\section{Urinary steroid profiling}

The USP of ACA-RML revealed no unusual patterns and the cases clustered with ACA and not with ACC. When compared with ACA (regardless of the inclusion or not of ACA with
Conn's syndrome), no statistically significant differences for any individual steroid or index could be demonstrated. However, there appeared to be a trend for ACA-RML towards decrease in dehydroepiandrosterone (DHA) and DHA metabolites (Fig. 2) whether graphed as individual steroids, expressed as a total of DHA and DHA metabolites or as a ratio related to total cortisol metabolites (Fig. 3). 16 $\alpha$-Hydroxy DHA showed a greater difference than DHA, suggesting a decrease in 16a-hydroxylation activity in ACA-RML. However, a ratio of $16 \alpha$-hydroxylated vs. non-16 $\alpha$-hydroxylated DHA metabolites was not different between ACA-RML and ACA.

Urinary steroid profiling analysis revealed statistically significant differences between both ACA groups (i.e.: ACA and ACARML) and the ACC group. ACC patients had higher excretion of numerous steroids, especially metabolites of steroid pathway intermediates. Those with the greatest differences are shown in Fig. 4, while the differences for DHA and DHA metabolites were also all significant (Fig. 3).

\section{Discussion}

ACA-RML represents a distinctive benign adrenocortical neoplasm for which the USP findings cluster with ACA. Although both the variability and rarity of this condition preclude firmer conclusions, the USP suggests an impaired DHA metabolic pathway with relatively preserved cortisol biosynthesis. Both age and ACTH (adrenocorticotroph hormone) suppression can contribute to this finding. Secretion of adrenal steroids, especially DHA and its sulphate, declines with age. ${ }^{10,17}$ Given that the ACA-RML group is older than the ACA group (Table 1), it is possible that the decrease in total C19 steroid sulphate (C19SS) metabolites and the increased cortisol metabolites (FM)/C19SS ratio are age related. However, sample numbers were too few to be able to apply procedures such as stepwise regression analysis to examine the influence of age. No glucocorticoid suppression testing was undertaken in the ACA-RML group, so the contribution of the tumour tissue to steroid secretion cannot be estimated. Likewise any

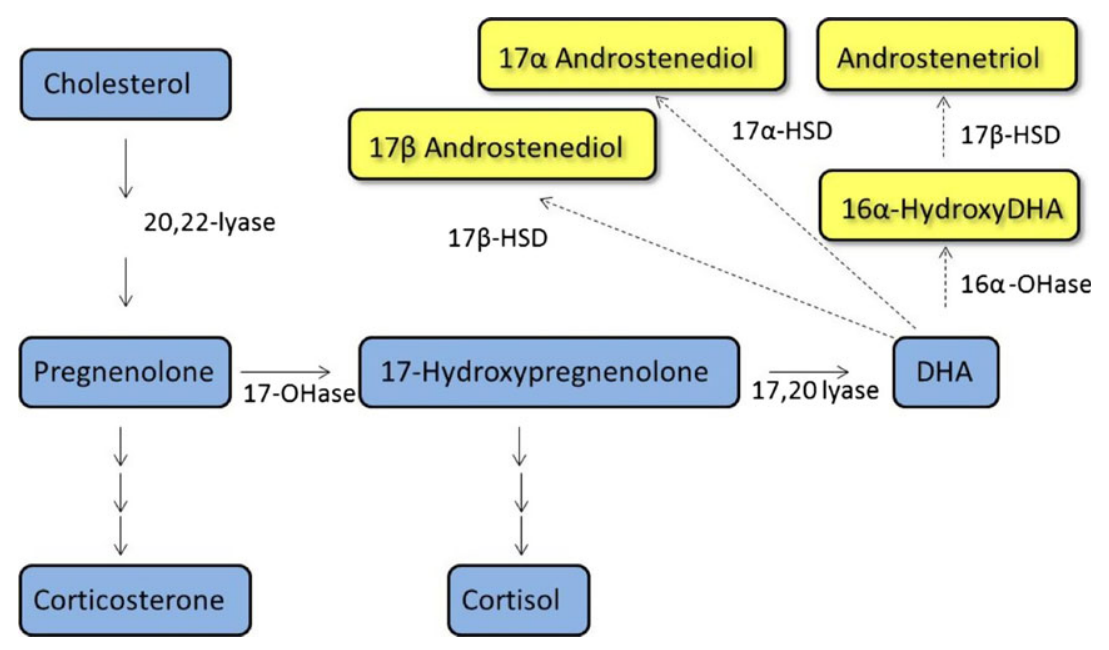

Fig. 2 C19SS metabolic pathway. 
Fig. 3 Comparison of patient groups: C19 steroid sulphates metabolites: -ACA vs ACC: $* P<0.05$, $* * P<0.01$. -ACA-RML vs ACC: $* * P<0 \cdot 01$, $* * * P<0.001 . \mathbf{\Lambda}, \mathbf{\Delta} \mathbf{\Delta}, \mathbf{\Delta} \mathbf{\Delta}$ : Not significant for the comparison ACA vs ACA-RML. Only asterisks comparison were significant, all remaining (triangles) were found not significant.
Dehydroepiandrosterone (DHA)

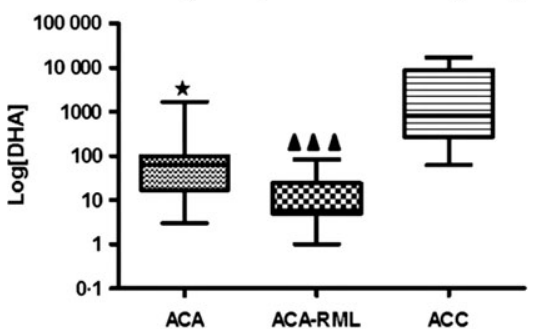

Androstenetriol (DA3)

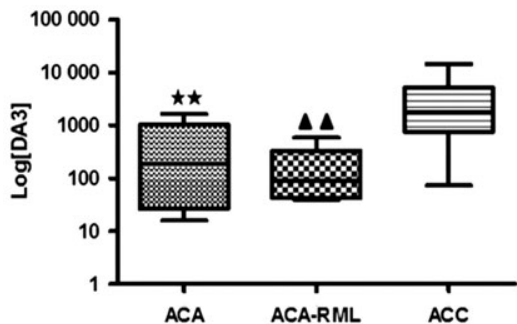

C19 steroid sulphates

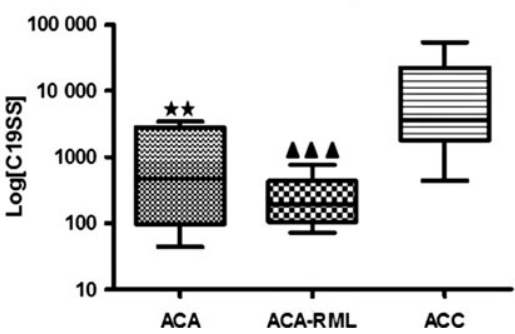

$16 \mathrm{OH}$-dehydroepiandrosterone

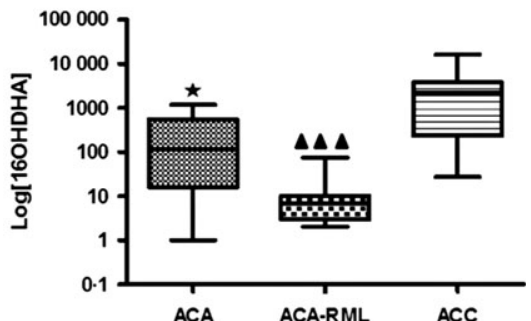

17-beta-androstenediol

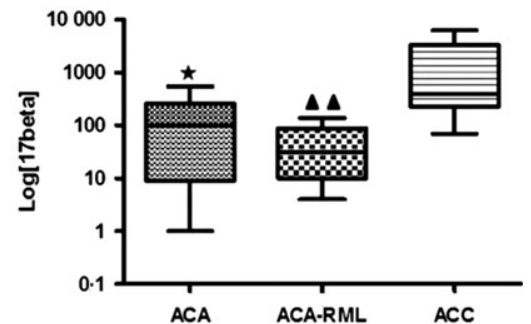

FM/C19SS

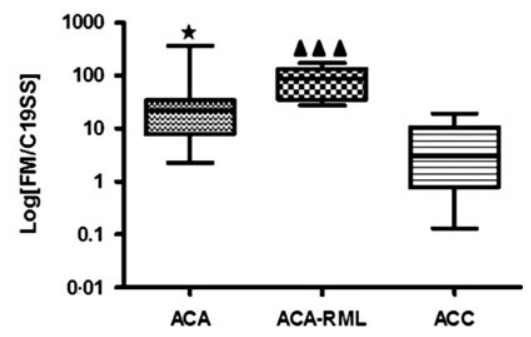

contribution of tumour tissue to further metabolism of steroids arising in normal adrenocortical tissue cannot be gauged. In our series, the majority of the ACA and ACARML had ACTH-independent Cushing's syndrome. As DHA is secreted from the normal cortex and the abnormal secretion is usually along a single pathway (glucocorticoid, mineral cor- ticoid or androgen), low DHA and DHA metabolites levels may reflect ACTH suppression; however, ACTH independent mechanisms must also be considered from secretory adrenal neoplasms. Conversely in the ACC, it is common for multiple steroidogenic pathways to be upregulated independently of $\mathrm{ACTH}$, hence the different profile. However, the values are
Fig. 4 Comparison of patient groups: steroid precursor metabolites: -ACA vs ACC: $* * * P<0 \cdot 01$, $* * * P<0.001$. -ACA-RML vs ACC: $* P<0.05$, $* * P<0.01, * * * P<0.001$. $\mathbf{\Delta}, \mathbf{\Delta} \mathbf{\Delta}, \mathbf{\Delta} \mathbf{\Delta}$ : Not significant for the comparison ACA vs ACA-RML. Only asterisks comparison were significant, all remaining (triangles) were found not significant.
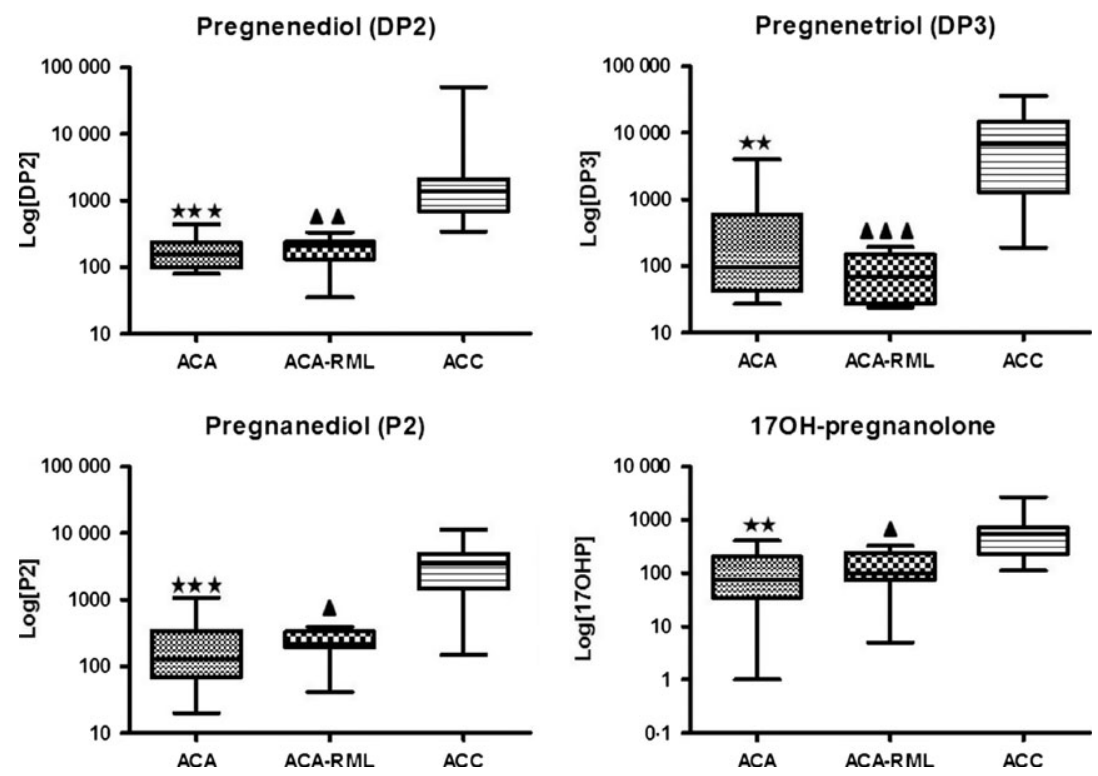
much lower for ACA-RML and they cannot be explained by ACTH suppression only. Low secretion in DHA and metabolites in ACA-RML have a multifactorial origin. It cannot be argued that all DHA is from the normal cortex and that it will be due to ACTH suppression because Cushing's syndrome was not universally identified and cortical atrophy was not present in all cases: two patients presented with adrenal mass only. In addition, any regression analysis of this very rare subtype of ACA (with a reduced number of cases) will not result in any statistically significant differences. Considering the proportionally big size of these neoplasms, the ischaemic changes associated with the mass effect (stromal hyalinization, oedema) will be a major contributor to this low secretion, especially in combination with age, ${ }^{17,18}$ incomplete ACTH intratumoral functional activity ${ }^{19}$ and oxidative effect of mononuclear bone marrow cells. ${ }^{20-22}$

ACA is a proliferative lesion with low cellular turnover, along with heterogeneous kinetic and clonal profiles. ${ }^{23-25}$ The mitotic figure counting was significantly lower in ACA-RML than in ACA and revealed a higher frequency of apoptotic cells. This kinetic pattern corresponds with the right tail of regressive monoclonal ACA (low proliferation and high apoptosis), which frequently shows interstitial haemorrhage and myelolipomatous changes. ${ }^{23,24,26}$ These added interstitial features give rise to lesions greater in size and with heterogeneous appearance. ${ }^{8}$ ACA-RML tumours were of significantly larger size than ACA, presented in older patients and showed a similar incidence in males and females, unlike the common epidemiology in ACA.

USP profiles of ACA-RML do not show any of the ACC markers previously reported, such as increased steroid precursor metabolites (pregnenediol and pregnenetriol) or increased DHA metabolites. ${ }^{27}$ The evaluation of USP in adrenocortical neoplasms includes the identification of abnormal metabolites and/ or the presence of a heterogeneous background associated with partial enzymatic deficiencies; the former findings being more accurate predictors of a malignant diagnosis. The pathological heterogeneity contributes to this complexity, but no single marker or value on its own is pathognomonic of this disease. Although USP will be more widely used in the future, considering the low ACC incidence and its heterogeneity with several patterns, it is more likely that accurate interpretations would be more reliable from specialized centres.

Although no significant differences between the ACA-RML and the ACA groups were found, there is an apparent decrease in the C19SS metabolic pathway in the group of adenomas with regressive changes. ACA-RML typically presented in older patients (as compared to both ACA and ACC), with large adrenal masses that reveal some degree of radiological heterogeneity. These features lead to investigate a potentially malignant condition, for which the urine steroid profile can be valuable. Our results probed the absence of positive malignant markers to support a benign lesion. Like with other diagnostic tests, it cannot be expected $100 \%$ specificity and/or sensitivity and that is our experience with the USP for the diagnosis of ACC. For that reason, observation only would be advised with caution as we can be dealing with the odd case, and the surgical intervention must be individually evaluated and, if necessary, a less radical excision should always be considered. Although the absence of markers will not definitely exclude a malignant lesion, a less radical surgical intervention can be planned in advance; this is a more desirable option for elderly patients who are the most frequently affected by this tumour type.

In conclusion, ACA-RML reveals distinctive histological features, along with a regressive kinetics profile that may co-segregate with decreased DHA synthesis. Importantly, they lack USP markers of malignancy, so that clear distinction from ACC is possible without surgical intervention. These conditions are radiologically similar, so USP findings can be critical in determining treatment strategy.

\section{Acknowledgements}

Dorota Dworakowska was supported by the Foundation for Polish Science, within the 'Bridge' programme (POMOST/2012-5/ 3), cofinanced by European Union.

\section{Conflict of interest}

The authors of this manuscript have no competing financial interests. They have no commercial associations that might create a conflict of interest in connection with the submitted manuscript.

The protocol used in the study was approved by the Hospital Research Board and Ethical Committees and complied with their requirements.

\section{References}

1 Abiven, G., Coste, J., Groussin, L. et al. (2006) Clinical and biological features in the prognosis of adrenocortical cancer: poor outcome of cortisol-secreting tumors in a series of 202 consecutive patients. Journal of Clinical Endocrinology and Metabolism, 91, 2650-2655.

2 Aubert, S., Wacrenier, A., Leroy, X. et al. (2002) Weiss system revisited: a clinicopathologic and immunohistochemical study of 49 adrenocortical tumors. American Journal of Surgical Pathology, 26, 1612-1619.

3 Blanes, A. \& Diaz-Cano, S.J. (2007) Histologic criteria for adrenocortical proliferative lesions: value of mitotic figure variability. American Journal of Clinical Pathology, 127, 398-408.

4 Lau, S.K. \& Weiss, L.M. (2009) The Weiss system for evaluating adrenocortical neoplasms: 25 years later. Human Pathology, 40, 757-768.

5 Allolio, B. \& Fassnacht, M. (2006) Clinical review: adrenocortical carcinoma: clinical update. Journal of Clinical Endocrinology and Metabolism, 91, 2027-2037.

6 Assie, G., Antoni, G., Tissier, F. et al. (2007) Prognostic parameters of metastatic adrenocortical carcinoma. Journal of Clinical Endocrinology and Metabolism, 92, 148-154.

7 Newhouse, J.H., Heffess, C.S., Wagner, B.J. et al. (1999) Large degenerated adrenal adenomas: radiologic-pathologic correlation. Radiology, 210, 385-391. 
8 Montone, K.T., Rosen, M., Siegelman, E.S. et al. (2009) Adrenocortical neoplasms with myelolipomatous and lipomatous metaplasia: report of 3 cases. Endocrine Practice, 15, 128-133.

9 Kikuchi, E., Yanaihara, H., Nakashima, J. et al. (2000) Urinary steroid profile in adrenocortical tumors. Biomedicine \& Pharmacotherapy, 54(Suppl 1), 194s-197s.

10 Tiu, S.C., Chan, A.O., Taylor, N.F. et al. (2009) Use of urinary steroid profiling for diagnosing and monitoring adrenocortical tumours. Hong Kong Medical Journal, 15, 463-470.

11 Rockall, A.G., Babar, S.A., Sohaib, S.A. et al. (2004) CT and MR imaging of the adrenal glands in ACTH-independent cushing syndrome. Radiographics, 24, 435-452.

12 Lloyd, R., DeLellis, R., Heitz, P. et al. (2004) Pathology and Genetics of Tumours of Endocrine Organs. WHO Press, Geneva.

13 Lloyd, R.V., Douglas, B.R. \& Young, W.R.J. (2002) Endocrine diseases. American Registry of Pathology and the Armed Forces Institute of Pathology, Washington, DC.

14 Weiss, L.M. (1984) Comparative histologic study of 43 metastasizing and nonmetastasizing adrenocortical tumors. American Journal of Surgical Pathology, 8, 163-169.

15 Weiss, L.M., Medeiros, L.J. \& Vickery, A.L. Jr (1989) Pathologic features of prognostic significance in adrenocortical carcinoma. American Journal of Surgical Pathology, 13, 202-206.

16 Taylor, N.F. (2013) Urinary steroid profiling. Methods in Molecular Biology, 1065, 259-276.

17 Labrie, F., Belanger, A., Cusan, L. et al. (1997) Marked decline in serum concentrations of adrenal C19 sex steroid precursors and conjugated androgen metabolites during aging. Journal of Clinical Endocrinology and Metabolism, 82, 23962402.

18 Drucker, W.D. (1977) Biologic activity and metabolism of androgenic hormones: the role of the adrenal androgens. Bulletin of the New York Academy of Medicine, 53, 347-358.

19 Saez, J.M., Dazord, A. \& Gallet, D. (1975) ACTH and prostaglandin receptors in human adrenocortical tumors. Apparent modification of a specific component of the ACTH-binding site. The Journal of Clinical Investication, 56, 536-547.

20 Haroon, E., Raison, C.L. \& Miller, A.H. (2012) Psychoneuroimmunology meets neuropsychopharmacology: translational implications of the impact of inflammation on behavior. Neuropsychopharmacology, 37, 137-162.

21 Kiecolt-Glaser, J.K. (2010) Stress, food, and inflammation: psychoneuroimmunology and nutrition at the cutting edge. Psychosomatic Medicine, 72, 365-369.

22 Rahal, A., Kumar, A., Singh, V. et al. (2014) Oxidative Stress, Prooxidants, and Antioxidants: The Interplay. Biomed Research International, 2014, 761264.

23 Diaz-Cano, S.J., de Miguel, M., Blanes, A. et al. (2000) Clonality as expression of distinctive cell kinetics patterns in nodular hyperplasias and adenomas of the adrenal cortex. American Journal of Pathology, 156, 311-319.

24 Blanes, A. \& Diaz-Cano, S.J. (2006) DNA and kinetic heterogeneity during the clonal evolution of adrenocortical proliferative lesions. Human Pathology, 37, 1295-1303.

25 Diaz-Cano, S.J. (2000) Designing a molecular analysis of clonality in tumours. The Journal of Pathology, 191, 343-344.

26 Diaz-Cano, S.J., de Miguel, M., Blanes, A. et al. (2001) Contribution of the microvessel network to the clonal and kinetic profiles of adrenal cortical proliferative lesions. Human Pathology, 32, 1232-1239.

27 Arlt, W., Biehl, M., Taylor, A.E. et al. (2011) Urine steroid metabolomics as a biomarker tool for detecting malignancy in adrenal tumors. Journal of Clinical Endocrinology and Metabolism, 96, 3775-3784.

\section{Supporting Information}

Additional supporting information may be found in the online version of this article at the publisher's website. 


\section{SUPPLEMENTARY TABLES}

Table S1. Steroid metabolites quantitated and metabolic pathways

\section{Trivial name}

1. Androsterone

2. Etiocholanolone

3. Dehydroepiandrosterone

4. 17 $\alpha$-Androstenediol

5. 17 $\beta$-Androstenediol

6. $16 \alpha-$

Hydroxydehydroepiandrosterone

7. Androstenetriol

8. 11-0xoetiocholanolone

9. 11-Hydroxyandrosterone

10.11-Hydroxyetiocholanolone

11.Pregnanediol

12. Pregnanetriol

13.Pregnenediol

14. Pregnenetriol

15.17 $\alpha$-Hydroxypregnanolone

16.11-0xo-pregnanetriol

17. Tetrahydro-11dehydrocorticosterone

18. Tetrahydrocorticosterone 


\section{Allo-tetrahydrocorticosterone}

\section{Tetrahydrocortisone}

\section{Tetrahydrocortisol}

\section{Allo-tetrahydrocortisol}

\section{Cortisol}

\section{6 $\beta$-Hydroxycortisol}

\section{5. $\alpha$-Cortolone}

\section{6. $\beta$-Cortolone}

\section{7. $\beta$-Cortol}

\section{8. $\alpha$-Cortol}

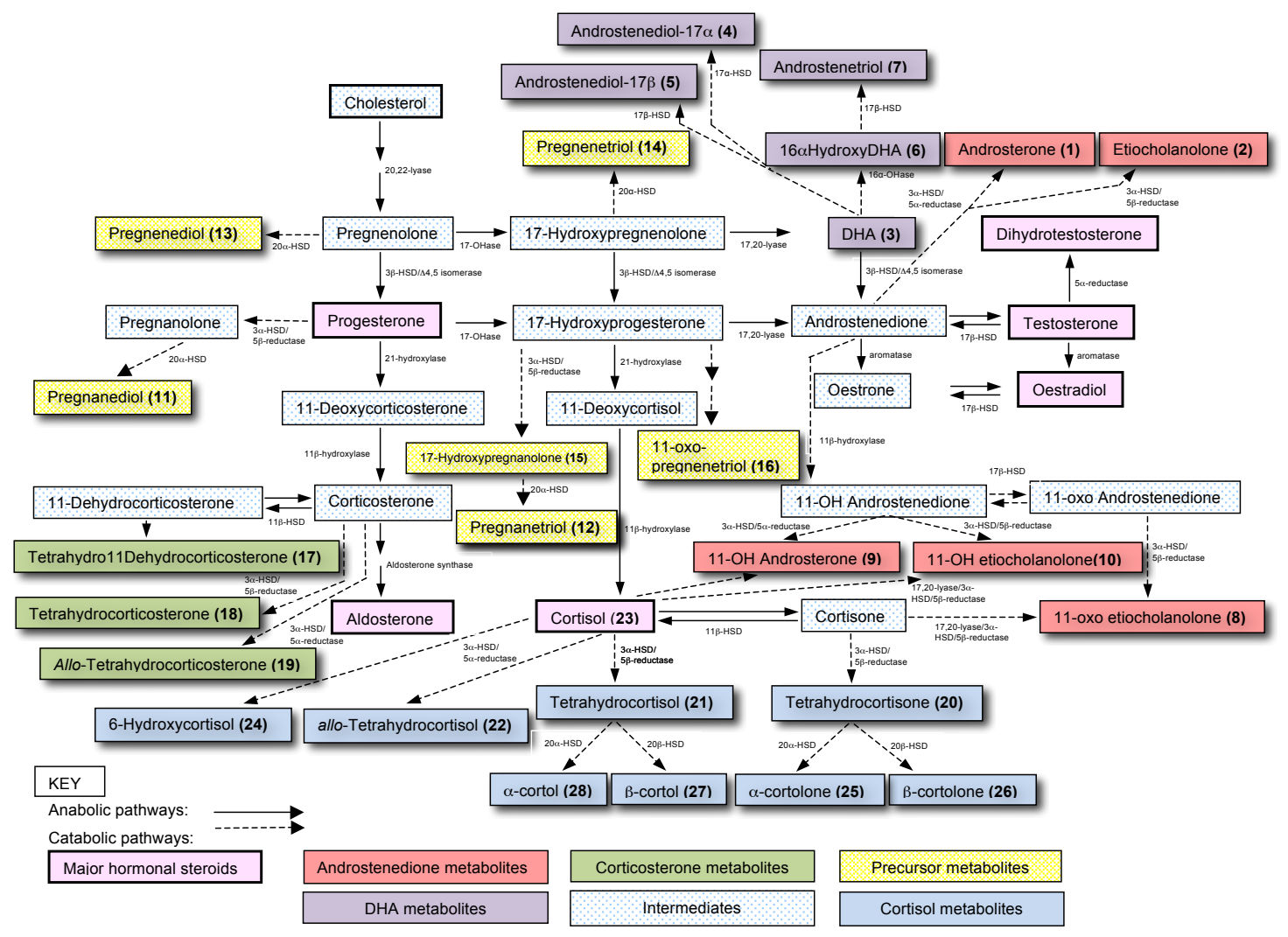


Table S2. Calculated sums and ratios.

\begin{tabular}{|c|c|c|}
\hline Ratio & Abbreviation & Formula \\
\hline Androgen metabolites & $\mathbf{A M}$ & $1+2+3$ \\
\hline Cortisol metabolites & FM & $\begin{array}{c}20+21+22+25+2 \\
6+27+28\end{array}$ \\
\hline Corticosterone metabolites & BM & $17+18+19$ \\
\hline Cortisone metabolites & EM & $20+25+26$ \\
\hline C19 Steroid sulphates & C19SS & $3+4+5+6+7$ \\
\hline \multirow{2}{*}{$\begin{array}{l}\text { 11-Hydroxyandrosterone/ } \\
\text { Cortisol metabolites }\end{array}$} & \multirow[t]{2}{*}{ 11A/FM } & (9) \\
\hline & & $\begin{array}{c}(20+21+22+25+ \\
26+27+28)\end{array}$ \\
\hline \multirow{2}{*}{$\begin{array}{l}\text { 11-Hydroxyetiocholanolone/ } \\
\text { Cortisol metabolites }\end{array}$} & \multirow[t]{2}{*}{ 11Ae/FM } & (10) \\
\hline & & $\begin{array}{c}(20+21+22+25+ \\
26+27+28)\end{array}$ \\
\hline \multirow{2}{*}{$\begin{array}{c}\text { 11-Hydroxyandrostenedione } \\
\text { metabolites/Cortisol } \\
\text { metabolites }\end{array}$} & \multirow[t]{2}{*}{ 11As/FM } & $(8+9+10)$ \\
\hline & & $\begin{array}{c}(20+21+22+25+ \\
26+27+28)\end{array}$ \\
\hline \multirow{2}{*}{$\begin{array}{c}5 \alpha \text { reduced } / 5 \beta \text { reduced } \\
\text { Androstenedione metabolites }\end{array}$} & \multirow[t]{2}{*}{ A/Ae } & (1) \\
\hline & & (2) \\
\hline \multirow{2}{*}{$\begin{array}{c}5 \alpha \text { reduced } / 5 \beta \text { reduced } \\
\text { 11-Hydroxyandrostenedione } \\
\text { metabolites }\end{array}$} & \multirow[t]{2}{*}{ 11A/11Ae } & (9) \\
\hline & & (10) \\
\hline 11-oxo/ 11-hydroxy & $110 \times 0 / 110 H$ & (8) \\
\hline
\end{tabular}




\begin{tabular}{|c|c|c|}
\hline Androstenedione metabolites & & $(9+10)$ \\
\hline \multirow{2}{*}{$\begin{array}{c}\text { Non 16-hydroxylated DHA } \\
\text { metabolites/ } \\
\text { 16-hydroxylated DHA } \\
\text { metabolites }\end{array}$} & \multirow{2}{*}{$\begin{array}{c}\text { Non/ } \\
\text { 160HDHAM }\end{array}$} & $(3+4+5)$ \\
\hline & & $(6+7)$ \\
\hline \multirow{2}{*}{$\begin{array}{l}20 \alpha \text { reduced } / 20 \beta \text { reduced } \\
\text { Cortisol metabolites }\end{array}$} & \multirow[t]{2}{*}{$20 \alpha / 20 \beta$} & $(25+28)$ \\
\hline & & $(26+27)$ \\
\hline \multirow{2}{*}{$\begin{array}{c}\text { 20-oxo Cortisol metabolites/ } \\
\text { 20-hydroxy Cortisol } \\
\text { metabolites }\end{array}$} & \multirow[t]{2}{*}{$200 \times 0 / 200 H$} & $(20+21+22)$ \\
\hline & & $(25+26+27+28)$ \\
\hline \multirow{2}{*}{$\begin{array}{c}5 \alpha \text { reduced } / 5 \beta \text { reduced } \\
\text { Cortisol metabolites }\end{array}$} & \multirow[t]{2}{*}{ aTHF/THF } & $(22)$ \\
\hline & & (21) \\
\hline \multirow{2}{*}{$\begin{array}{l}\text { Tetrahydrocortisone/ } \\
\text { Tetrahydrocortisols }\end{array}$} & \multirow[t]{2}{*}{ THE/THFs } & (20) \\
\hline & & $(21+22)$ \\
\hline \multirow{2}{*}{$\begin{array}{c}\text { 17-Hydroxyprogesterone } \\
\text { metabolites/Cortisol } \\
\text { metabolites }\end{array}$} & \multirow[t]{2}{*}{ 17PM/FM } & $(12+15)$ \\
\hline & & $\begin{array}{c}(20+21+22+25+ \\
26+27+28)\end{array}$ \\
\hline \multirow[t]{2}{*}{$\begin{array}{l}\text { Cortisol metabolites/ } \\
\text { Androgen metabolites }\end{array}$} & \multirow[t]{2}{*}{ FM/AM } & $\begin{array}{c}(20+21+22+25+ \\
26+27+28)\end{array}$ \\
\hline & & $(1+2+3)$ \\
\hline \multirow[t]{2}{*}{$\begin{array}{l}\text { Cortisol metabolites/ } \\
\text { C19 steroid sulphates }\end{array}$} & \multirow[t]{2}{*}{ FM/C19SS } & $\begin{array}{c}(20+21+22+25+ \\
26+27+28)\end{array}$ \\
\hline & & $(3+4+5+6+7)$ \\
\hline \multirow{2}{*}{$\begin{array}{l}\text { Cortisone metabolites/ } \\
\text { Cortisol metabolites }\end{array}$} & \multirow[t]{2}{*}{ EM/FM } & $(20+25+26)$ \\
\hline & & $(21+22+27+28)$ \\
\hline \multirow[t]{2}{*}{$\begin{array}{c}\text { Cortisol metabolites/ } \\
\text { Corticosterone metabolites }\end{array}$} & \multirow[t]{2}{*}{$\mathbf{F M} / \mathbf{B M}$} & $\begin{array}{c}(20+21+22+25+ \\
26+27+28)\end{array}$ \\
\hline & & $(17+18+19)$ \\
\hline
\end{tabular}

